\title{
A BATTERY CHARGING STRATEGY IN PHOTOVOLTAIC SYSTEMS USING FUZZY LOGIC CONTROL.
}

\author{
*Mahmoud Raafat Ebead, Walaa Ibrahim Gabr \\ and Mahmoud Mohamed ELBahy
}

Department: Electrical Eng. Department - Benha Faculty of Eng., Benha University, Egypt. *Corresponding author E-mail: eng.controller.mr@gmail.com,

\section{ABSTRACT}

Battery charging control is the most important part in Stand-Alone PV system, because it is responsible for the performance of the system. There are two types of charger controllers, the first is the pulse width modulation (PWM) and the second is the maximum power point tracking (MPPT).This paper introduces a charging strategy that improves the efficiency of battery charging process and enhances the battery life by using the PWM technique. An experimental proposed fuzzy logic module is embedded in a microcontroller. The measured response showed smooth charging especially during critical phase of battery charging and preventing the battery bank from any overcharging , undercharging and sulfation.

Keywords: Charging, off grid PV systems, Fuzzy Logic Controller,

\section{Pulse Width Modulation, Trickle Charging.}

" الضبابي

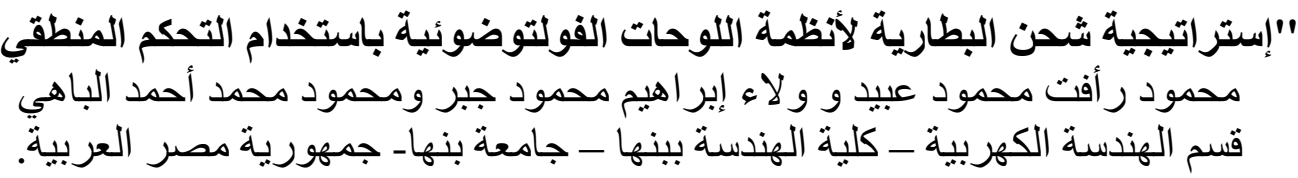

الملخص:

يعد التحكم في شحن البطارية لأنظمة اللوحات الفولتوضوئية المنفصلة من أهم الأجزاء داخل النظام، نظر الكوان لكونه

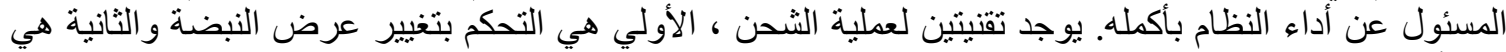

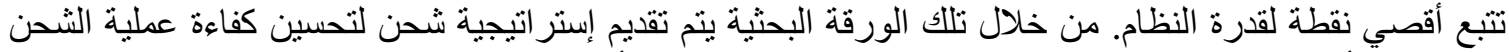

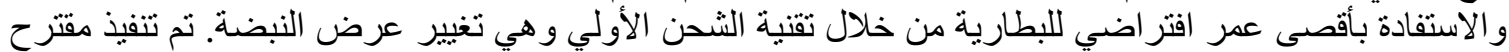

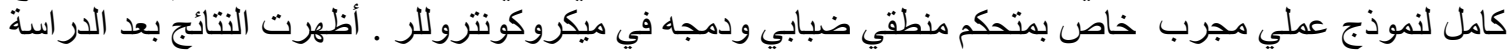

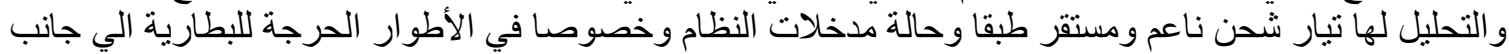

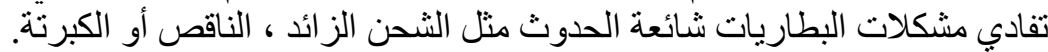

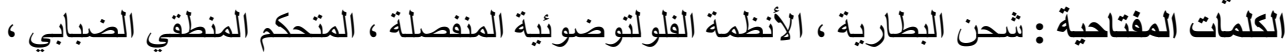
تضمين عرض النبضة ، الثحن بالتقطير الكهربي.

\section{INTRODUCTION}

PWM is the most effective technique to achieve constant voltage battery charging [1]. And this is by switching power devices of the solar system controller. The current from the solar array tapers according to the battery's condition and recharging needs. 
Charging a battery with a solar system is a unique and difficult challenge. In the early beginning of integrating the PV systems with the micro grid,_simple on-off regulators were used to prevent the battery from outgassing [2]. That is especially occurring when a solar panel produced excess and high energy. However, as solar systems matured, it became clear how much these simple devices interfered with the charging process. The history of on-off regulators has been suffered early battery failures, increasing load disconnection, and growing user dissatisfaction. PWM has recently surfaced as the first significant advance in solar battery charging.

PWM charging controllers use technology near to the other modern high quality battery chargers such as MPPT. When a battery voltage reaches the regulation set point, the PWM algorithm slowly reduces the charging current to avoid heating and gassing of the battery. Then the charging continues to return the maximum amount of energy to the battery in the shortest time. The result is a higher charging efficiency, rapid recharging rate, and a healthy battery at full capacity.

The batteries are considered an important part in PV systems. This is Because of its cost "especially the special types (deep cycle) that are recommended for use in PV systems". Besides, it is the only energy source in sun absence periods [3]. According to our application conditions, the sealed lead acid battery (AGM - Absorbed Glass Mats type) was used in the proposed system. In AGM battery the electrolyte in it is absorbed in glass mats which are sandwiched in layers between the plates [4].

Charger controller is the device that controls and improves the performance and behavior of PV systems. It is responsible for preserving the battery bank and increasing the PV panel's efficiency to obtain a stable output [5].

PWM technique has many advantages. It reduces the cost and the battery disposal problems. Also, it increases the reliability of the solar system [6]. All PWM chargers are not the same. The proposed charging strategy improves the performance of the PWM technique by designing and implementing a fuzzy module. The module reads the real time battery voltage, currents and the ambient temperature. Then fuzzy logically controls the battery charging current by pulse width modulation (PWM) technique.

In many recent researches, many technical problems were solved. But these solutions were accompanied by some complexity in its mathematical models, high cost and mismatching with the local climate in an accepted way. This research is a try to adapt with the modern battery chargers. A fully proposed PWM charger controller was designed and implemented. The objective is to verse and regulate all the battery's performance affecting parameters and conditions (Volt, Current and Ambient temperature). It is also supposed to avoid any complexity and match with the local climate for having the most energy benefits of the proposed system.

\section{SYSTEM CONFIGURATION AND EQUIPMENT.}

The main scope of this research is designing and implementing a battery charger controller of a Stand-Alone PV system. For minimizing the charging time and enhancing the battery life, the system shown in Fig.1 was designed and implemented. The following main equipments were used: 


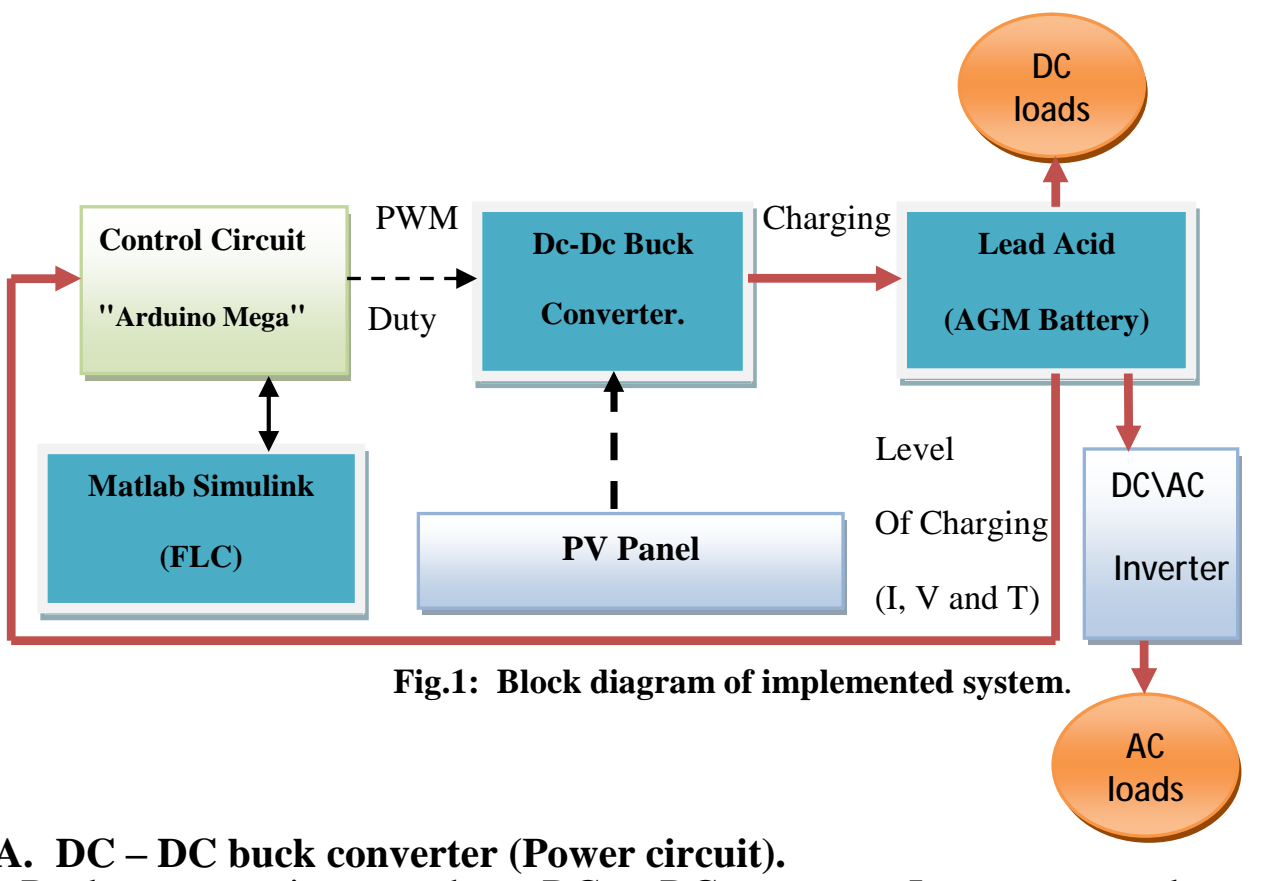

\section{A. DC-DC buck converter (Power circuit).}

A Buck converter is a step-down DC-to-DC converter. It converts a voltage source into a lower regulated voltage in the same polarity and is not isolated between the input and output [7]. The input current is discontinuous due to the power switch MOSFET current that pulses from zero to an output current every switching cycle. The output current is continuous because the current is supplied by the output inductor and capacitor combination [8]. This DC-to-DC converter was fully designed and implemented in this study. The key parameters (Appendix 1) were used in designing the proposed buck converter shown in Fig.2.

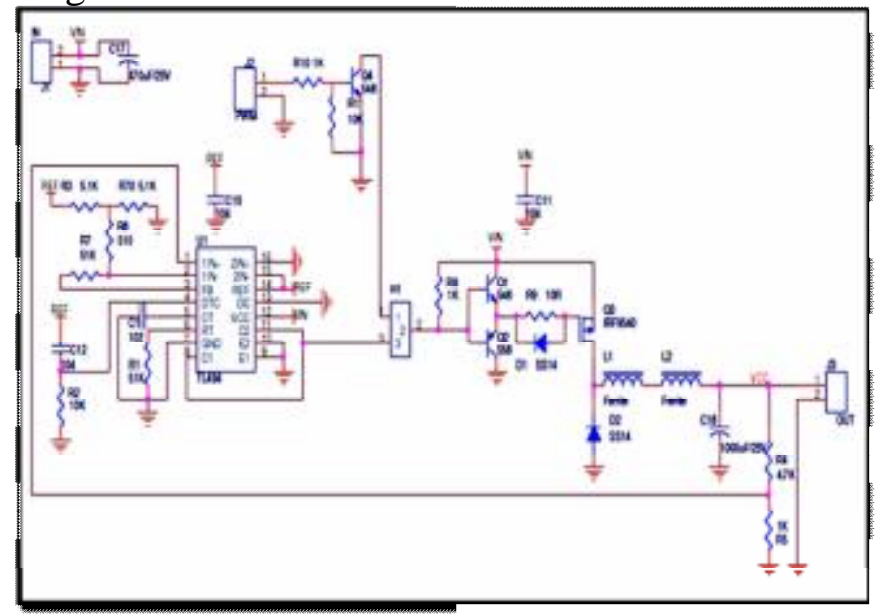

Fig.2: Schematic diagram of executed buck converter.

As shown in Fig.3 and Fig.4, The proposed buck converter was introduced with its main components values and then the final executed printed circuit board of it. 


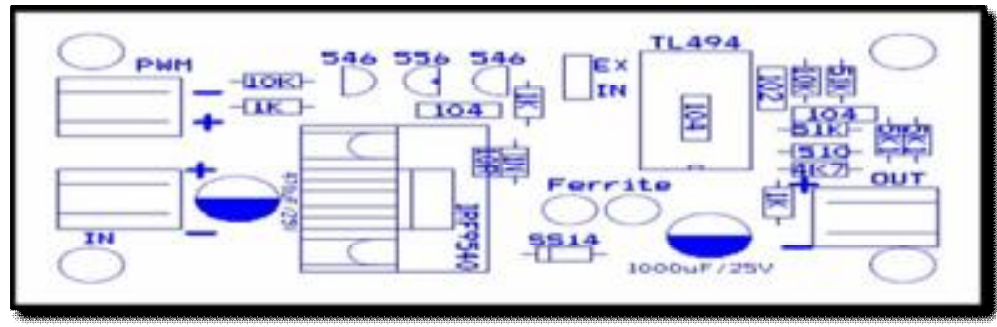

Fig.3: Executed buck converter with its main components values.

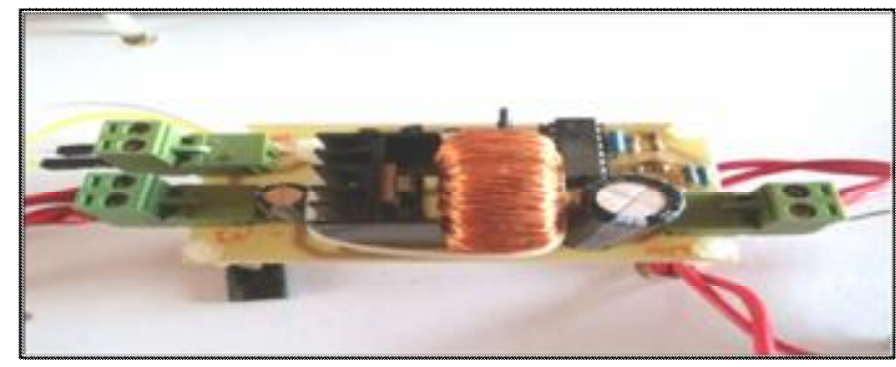

Fig.4: Executed buck converter after printing and assembling.

\section{B. Controller - Arduino mega 2560 (Control circuit).}

The Arduino Mega 2560 is a microcontroller board based on the ATmega2560. It has 54 digital input/output pins (of which 14 can be used as PWM outputs), 16 analog inputs, 4 UARTs (hardware serial ports), a $16 \mathrm{MHz}$ crystal oscillator, a USB connection, a power jack, an ICSP header, and a reset button. It contains everything needed to support the microcontroller; simply connect it to a computer with a USB cable or power it with an AC-to-DC adapter or battery to get started [6]. Here is the main technical specification of the used unit.

Table 1: Arduino Mega2560 main technical specifications.

\begin{tabular}{|l||l||}
\hline $1-$ Microcontroller & ATmega2560 \\
\hline 2- Operating Voltage & $5 \mathrm{~V}$ \\
\hline 3- Input Voltage & $7-12 \mathrm{~V}$ \\
\hline 4- Digital I/O Pins & 54 (of which 14 provide PWM output) \\
\hline 5- Analog Input Pins & 16 \\
\hline 6- DC Current per I/O Pin & $40 \mathrm{~mA}$ \\
\hline 7- Clock Speed & $16 \mathrm{MHz}$ \\
\hline
\end{tabular}

\section{PV panel and Battery.}

In the proposed system, Solar module 50W Mono solar (Single Crystal) Panel was used as shown in Fig.5 with Nominal Power $P_{\max }=50 \mathrm{~W}$, Voltage $V_{m p}=18 \mathrm{~V}$, Current $I_{m p}=2.8 \mathrm{~A}$, Voltage Open Circuit $V_{o \sigma}=22 \mathrm{~V}$, Short Circuit Current $I_{s o}=3 \mathrm{~A}$, by using also Sealed VRLA (AGM - Deep Cycle) battery as shown in Fig.6 with 7.2 AH, $12 \mathrm{~V}$ (Deep Cycle), Voltage regulation in standby use is (13.7-13.9 $\mathrm{V}$ ) and initial current is (2.16A), AGM (absorbed glass mate type). 


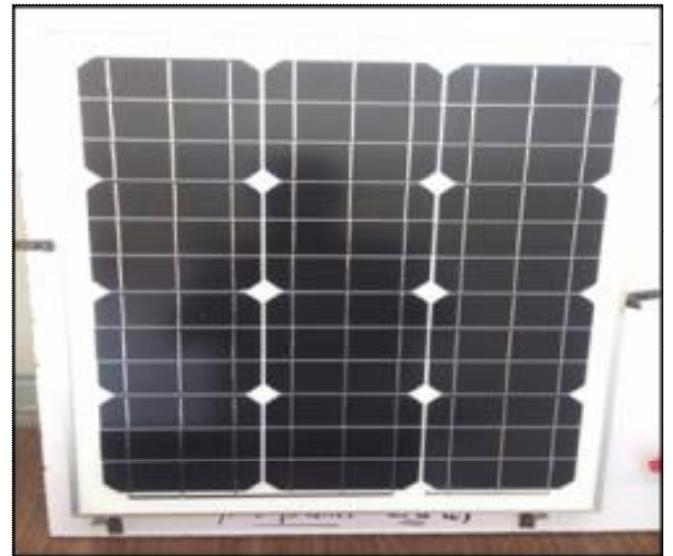

Fig.5: 50W MONO solar panel.

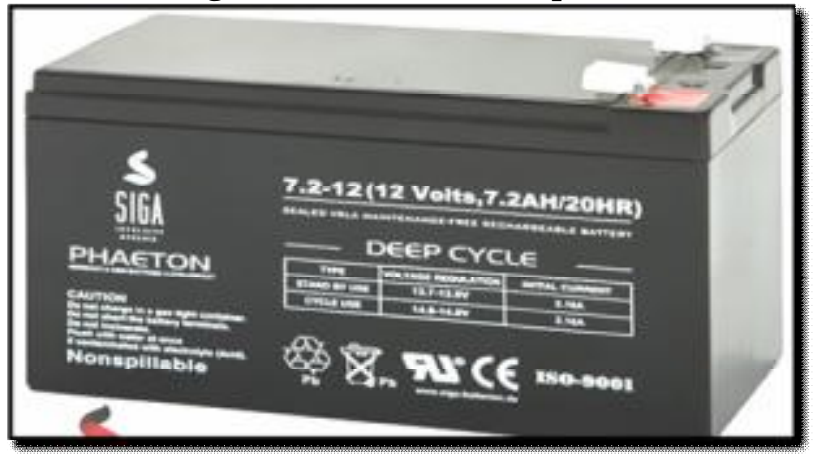

Fig.6: The used battery in the proposed system.

\section{METHODOLOGY.}

After designing the PV system using the above illustrated components, the system was installed and the following measurements and observations were recorded. The proposed module is composed of main parts as will be given in the following four items:

\section{A. Input parameters.}

- Reading the battery voltage.

As it cannot apply voltage of value higher than $5 \mathrm{~V}$ to the arduino analog input module [10], therefore, a voltage divider circuit was designed to overcome this problem. A voltage divider involves applying a voltage across a series of two resistors with the values of 1000 and $560 \mathrm{ohm}$ as shown in Fig.7.

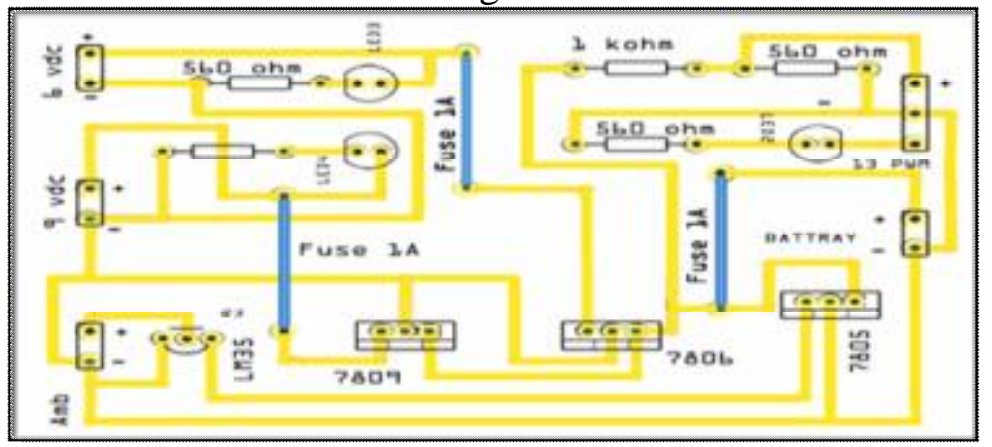

Fig.7: Circuit diagram of input and output printed circuit board. 
- Reading the current (charging or discharging).

Fully Integrated, Hall Effect-Based Linear Current Sensor ACS712 is used and connected with the used arduino board. The sensor consists of a precise, low-offset, linear Hall circuit with a copper conduction path located near the surface of the die.

Applied current flowing through this copper conduction path generates a magnetic field, which the Hall IC converts it into a proportional voltage. Device accuracy is optimized through the close proximity of the magnetic signal to the Hall transducer [10].

- Reading the ambient temperature.

LM35 temperature sensor is used and connected it with the analog input of the arduino board as shown in Fig.8.

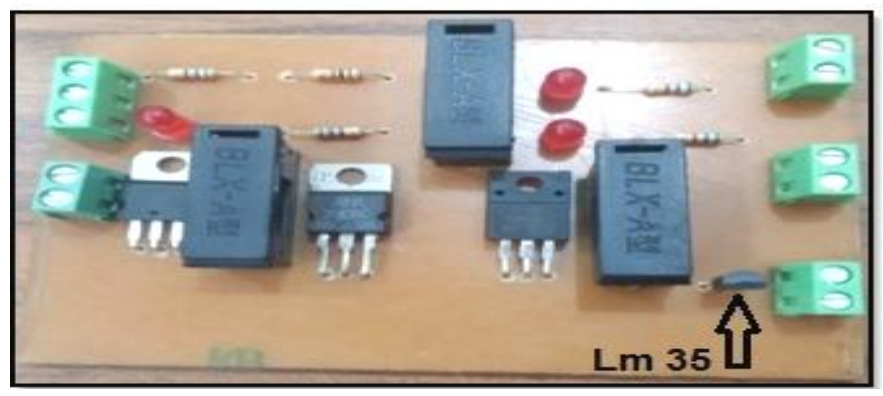

Fig.8: LM 35 temperature sensor in input and output printed circuit board.

\section{B. Output parameter.}

- PWM output signal.

Pulse Width Modulation (PWM) is a method to provide a variable signal from a given set signal. This can be achieved by changing the pulse width, which in turn, changes the duty cycle of a square wave to alter how much power is supplied to the attached component. It varies because the signal takes the duty cycle and averages the power signal [12]. So the larger the duty cycle percentage, the larger the output signal will be as given in (Appendix 2). The PWM default frequency of arduino mega 2560 is $470 \mathrm{~Hz}$ for all pins, with the exception of pin 13 and 4 which frequency is $980 \mathrm{~Hz}$ [11].

\section{THE PROPOSED FUZZY LOGIC MODULE.}

Since the battery charging parameters show uncertainty nature, so applying fuzzy logic for those parameters would enhance the charging process. In the proposed fuzzy charging module [12], the battery volt is divided into two values. Each is defined by a different membership function. The first is the desired or a regulated value (from 13.7 to $14 \mathrm{~V} \mathrm{dc}$ ) as shown in Fig.9 which is specified by the battery manufacturer. the second is the critical values (less than $13.7 \mathrm{~V} \mathrm{dc}$ ). 


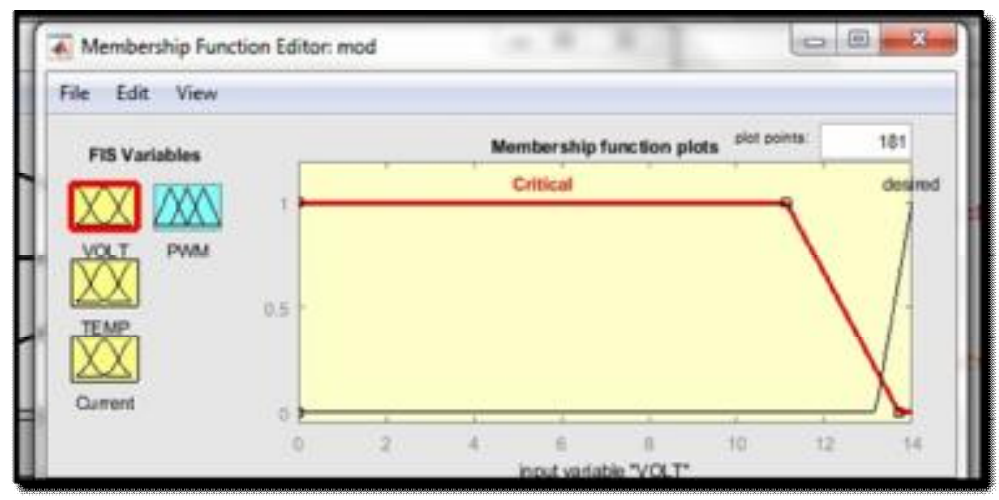

Fig.9: Fuzzy inference system variable (Volt).

The proposed charging strategy didn't depend on the battery volt only in evaluating the capacity of the battery bank. It also read the charging or the discharging current .the current is divided it into two ranges (low- from zero to $200 \mathrm{~mA}$ ) and (high- more than $200 \mathrm{~mA}$ ) each of different membership function as shown in Fig.10,.

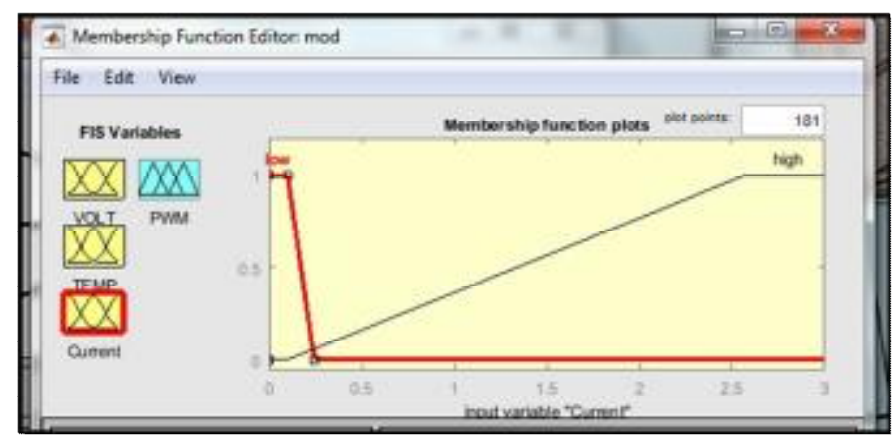

Fig.10: Fuzzy inference system variable (Current).

The ambient temperature of the environment that the battery will work on specifically is read as shown in Fig.11. It makes the proposed system smarter and more fixable. The efficiency, life time of the PV panel and the battery bank can be also improved. Temperature has important effects on performance. Generally, as the temperature increases by $10^{\circ} \mathrm{C}$ the rate of an electrochemical reaction doubles, battery life decreases by a factor of two for every $10{ }^{\circ} \mathrm{C}$ increase in average operating temperature. Higher operating temperatures accelerate corrosion of the positive plate grids, resulting in greater gassing and electrolyte loss [3].

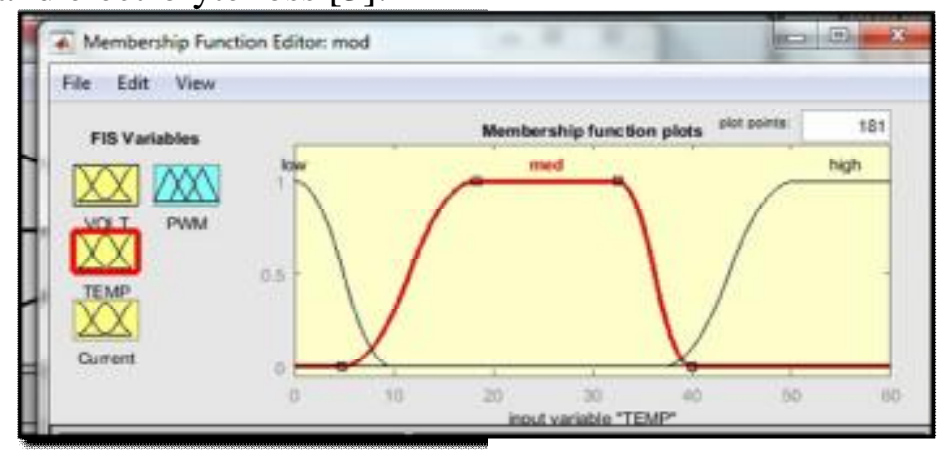

Fig.11: Fuzzy inference system variable (Temperature). 
The PWM output level as shown in Fig.12 is controlled by changing the duty cycle according to the inputs conditions. The control circuit was designed and implemented by using the arduino mega 2560 with its great advantage as a hardware open resource. The rduino is not only used to read the charger input parameters. It also connects the designed simulink model shown in Fig.13 with the controller. The proposed system is able to monitor the real time performance of all the system parameters on laptop [13]. The power circuit was designed and implemented (dc-dc buck converter). It is responsible for delivering the variable power from the PV panel to the battery after being regulated by the control signal. The rule and the surface viewer were used to test and enhance the performance and the response of the designed memberships function. As shown in Fig.14, Fig.15 the PWM output levels can be matched with the inputs conditions of the system.

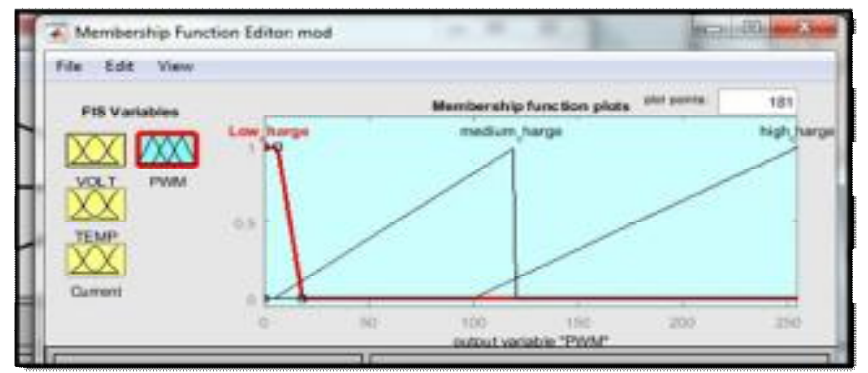

Fig.12: Fuzzy inference system variable (PWM).

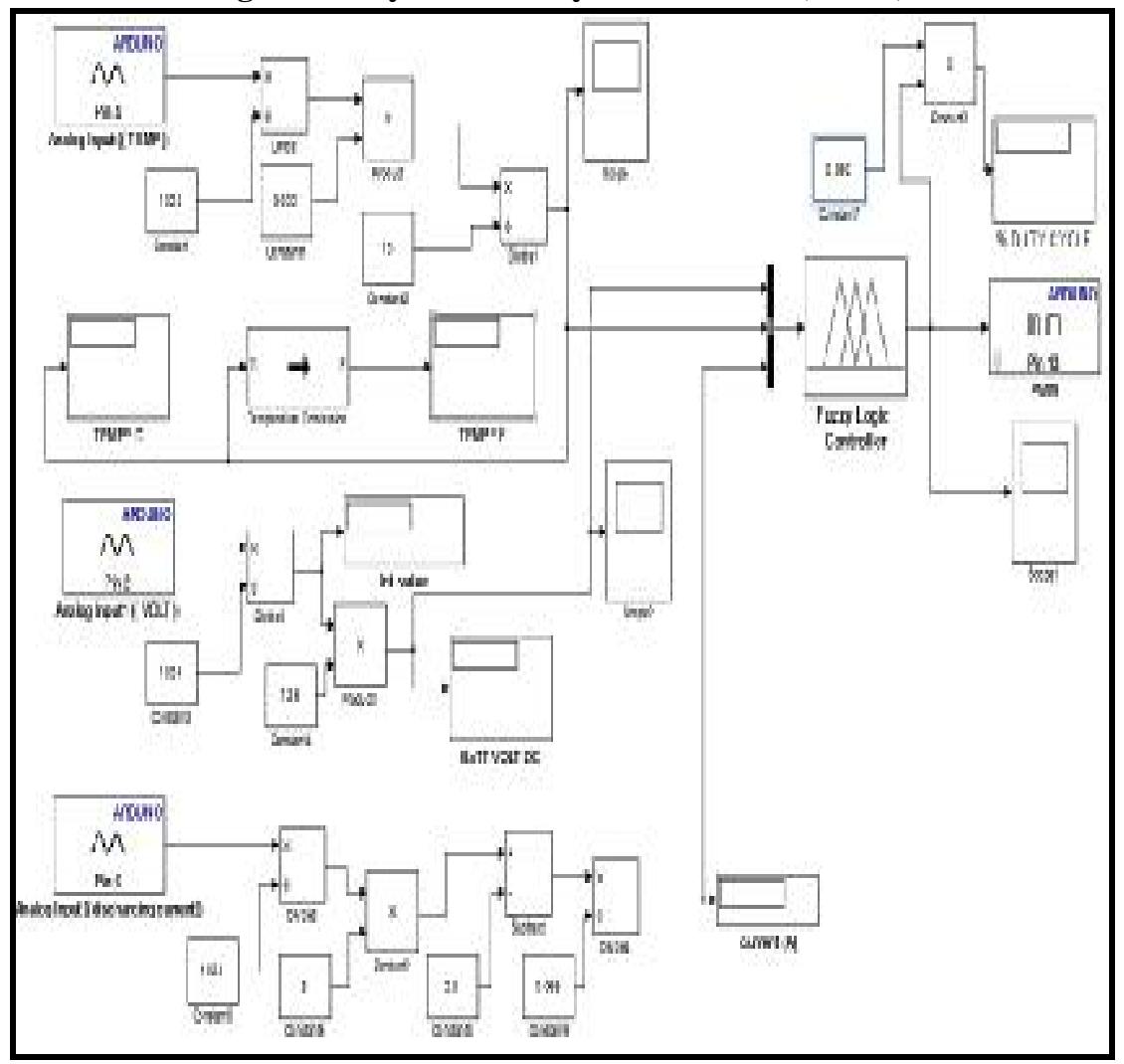

Fig.13: The designed proposed simulink model. 
A BATTERY CHARGING STRATEGY IN PHOTOVOLTAIC SYSTEMS USING FUZZY LOGIC CONTROL.

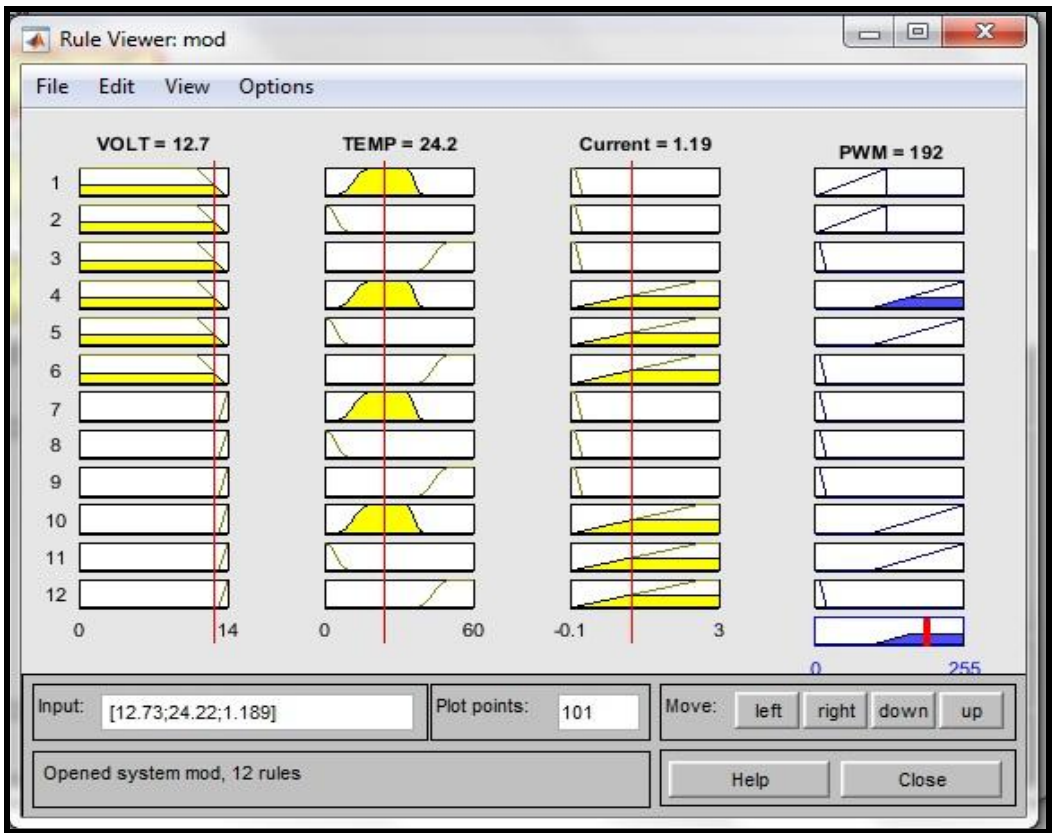

Fig.14: The rule viewer.

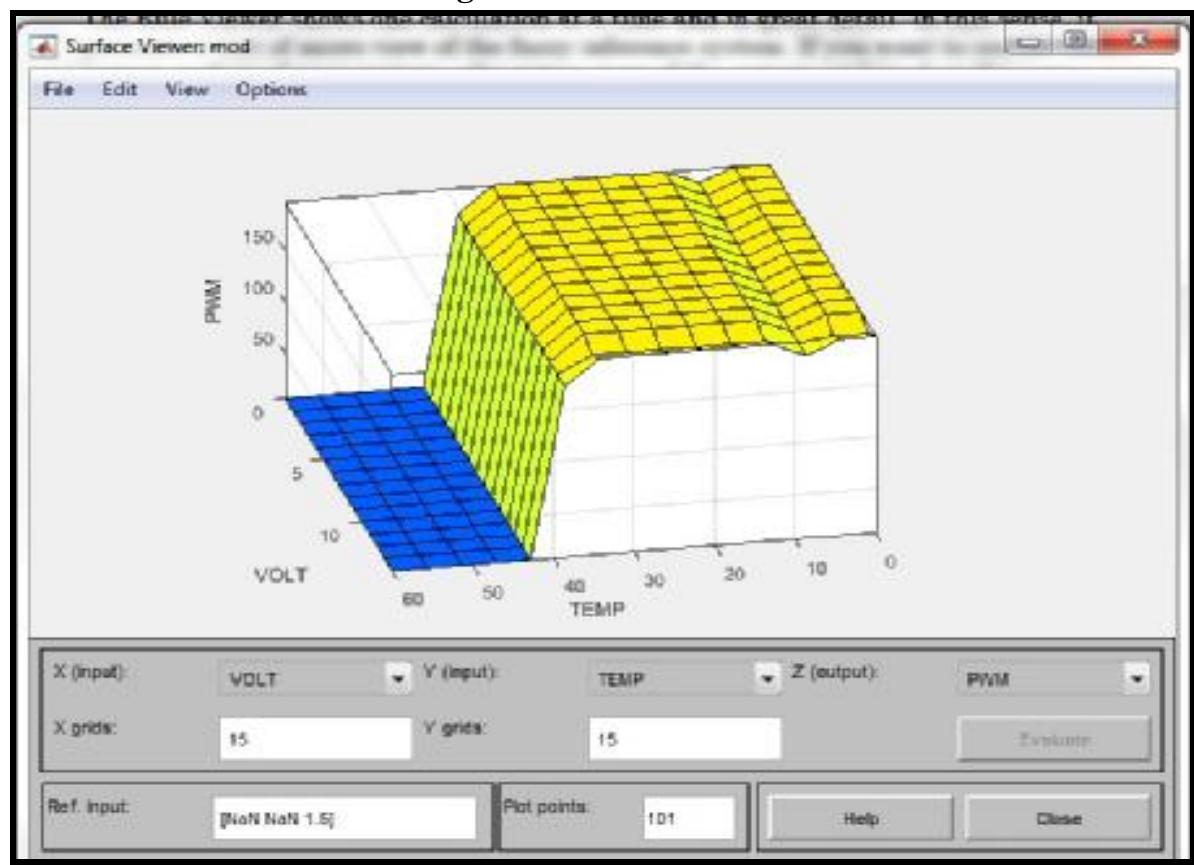

Fig.15: The surface viewer.

\section{Results and Analysis.}

After observing the performance of the proposed system, results were divided into all the three possible performance scenarios of the system. 


\section{A. Without charging and discharging current.}

After establishing the proposed simulink and connecting it with the system hardware, and by make running on target hardware successfully, it is able to monitor and control the proposed system. The system response will be practically showed with the next parameters: Ambient Temp. $21 \circ \mathrm{C}$ as shown in Fig.16 and Fig.17.

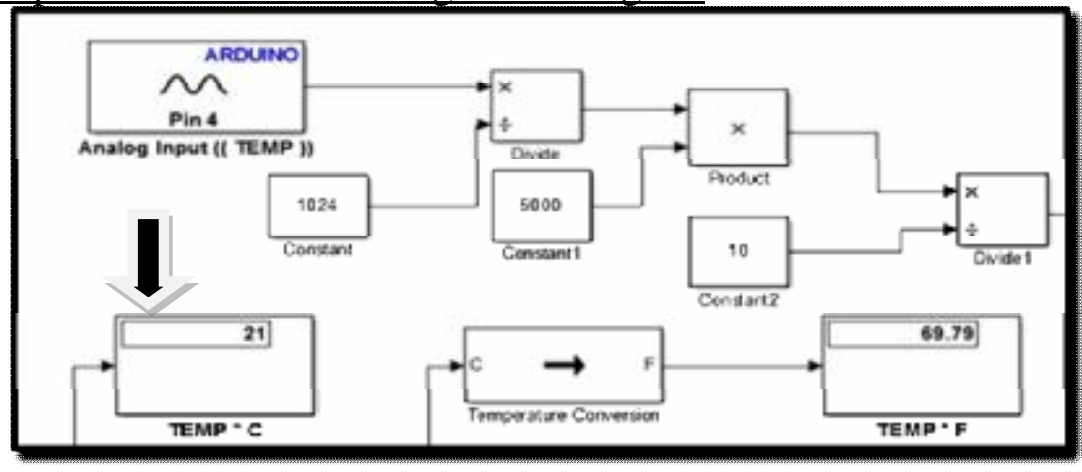

. Fig.16: Measuring of ambient temp

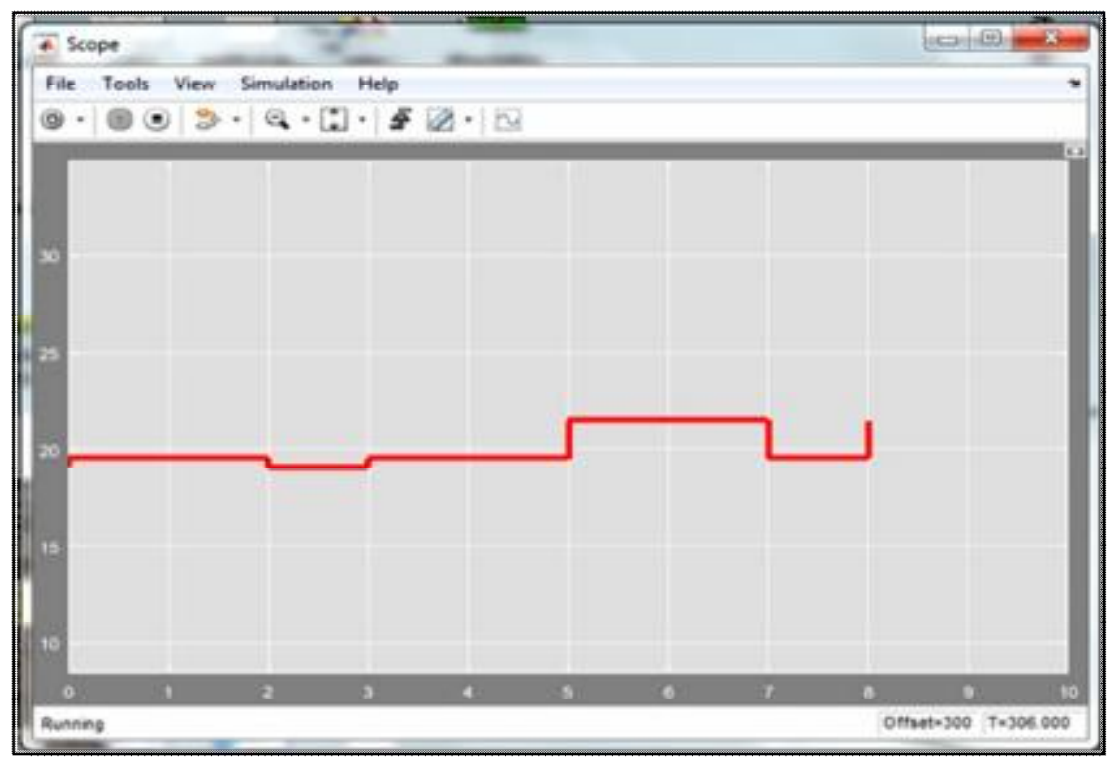

Fig.17: Ambient temp scope while running.

Battery Volt 12.14 Vdc. as shown in Fig.18 and Fig.19. 


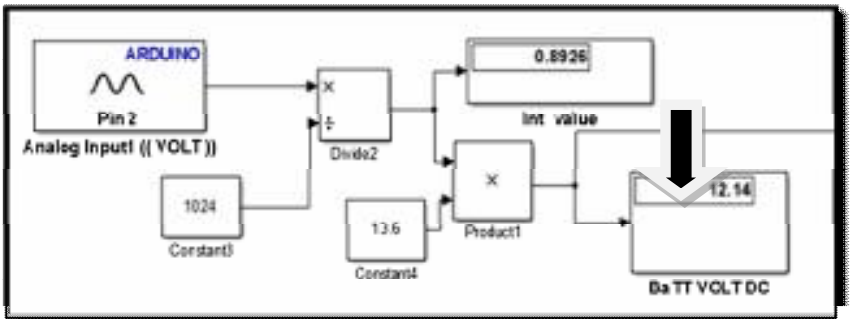

Fig.18: Battery Volt.

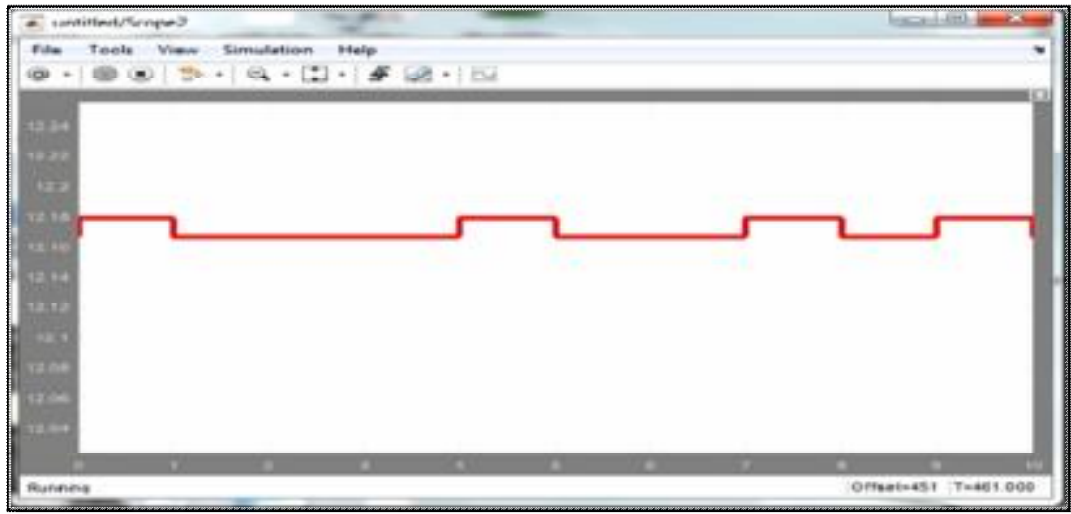

Fig.19: Battery Volt scope while running.

Zero Current nearly as shown in Fig.20.

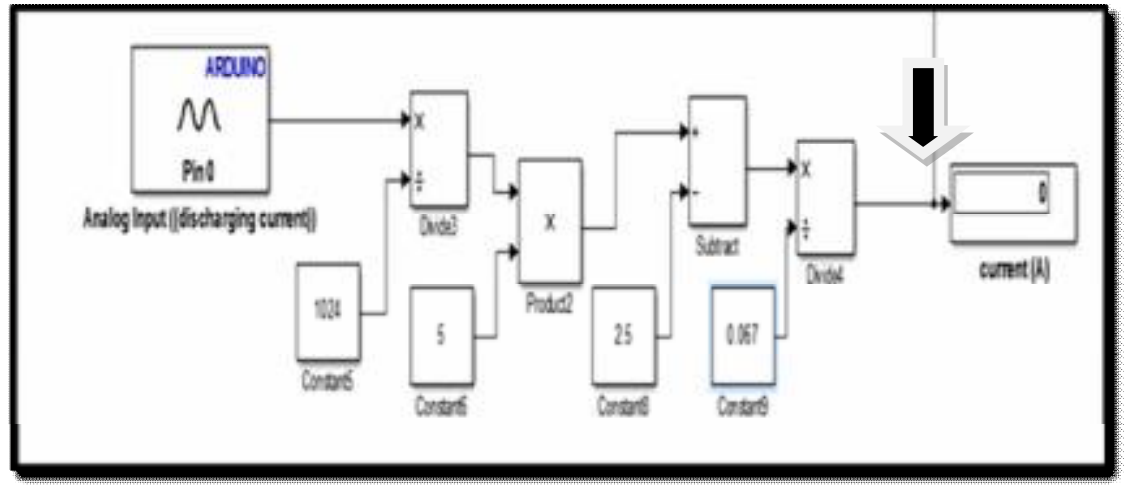

Fig.20: Charging or Discharging current .

With a critical value of the battery volt, medium ambient temperature and zero charging current as shown in Fig.21 we obtained (30.58\% duty cycle of the PWM output with level of 77 nearly). 


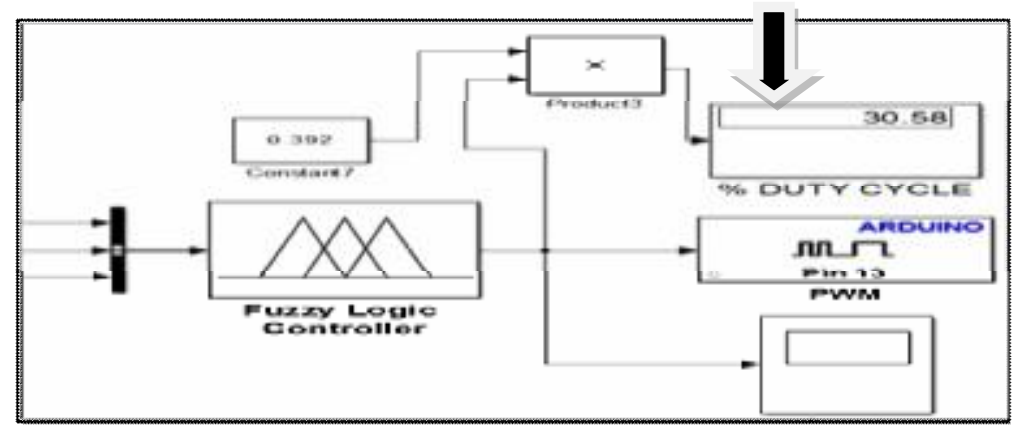

Fig.21: Output current with $30.58 \%$ duty cycle.

\section{B. Connecting of different loads.}

We connect the inverter (consuming 0.8 to $0.9 \mathrm{~A}-$ as shown in Fig.22) for using the ac loads. We charged our mobile phones successfully after seeing the accepted response of the system. It increased its PWM output level to 190 (74.65 \% duty cycle) as it is shown in Fig. 23.

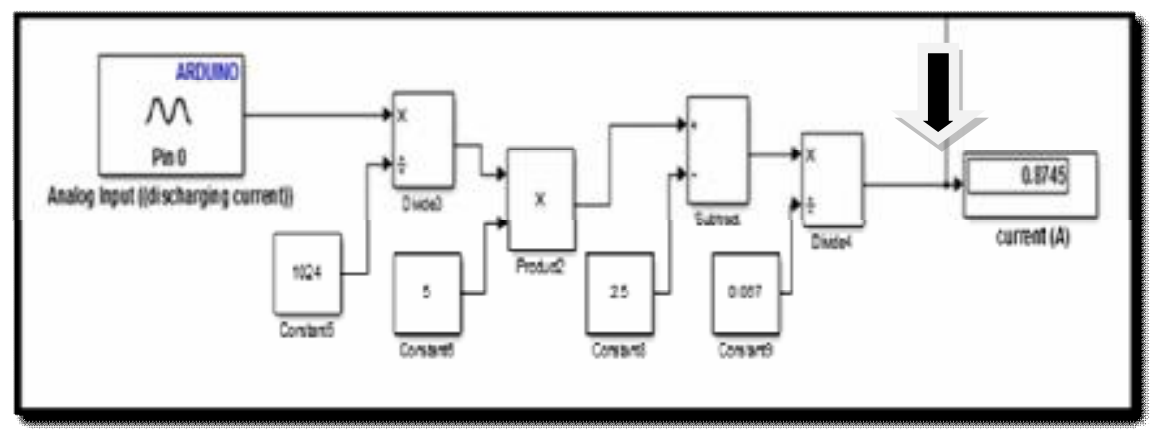

Fig.22: Connecting loads (Dc\Ac inverter)

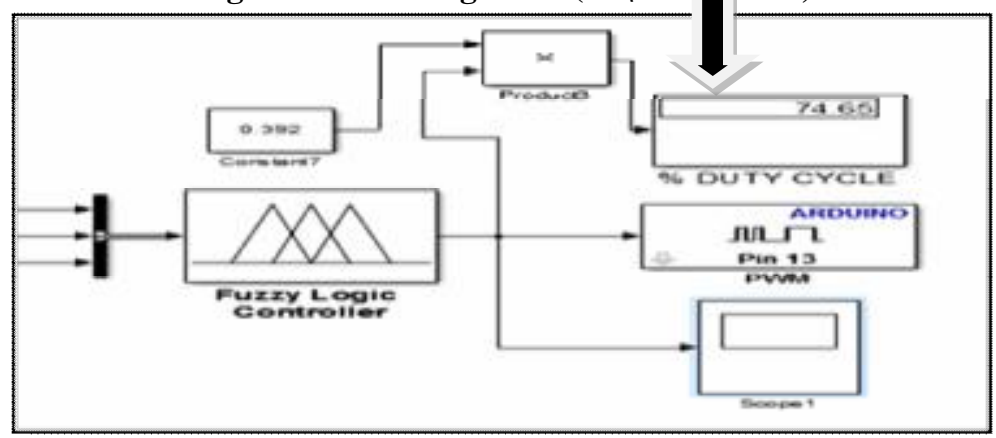

Fig.23: Output current with $\mathbf{7 4 . 6 5 \%}$ duty cycle.

\section{Variation (increasing) ambient temperature effect.}

We connected some different loads as shown in Fig.24 with sudden rising of the ambient temperature as it is illustrated in Fig.26 of the battery bank. The PWM decreased its output level directly to the level of rising. We were able to keep any critical loads working till avoiding the reason of the ambient temperature increasing.

Connecting our inverter and mobile charger $(\mathrm{I}=0.95 \mathrm{~A})$. 


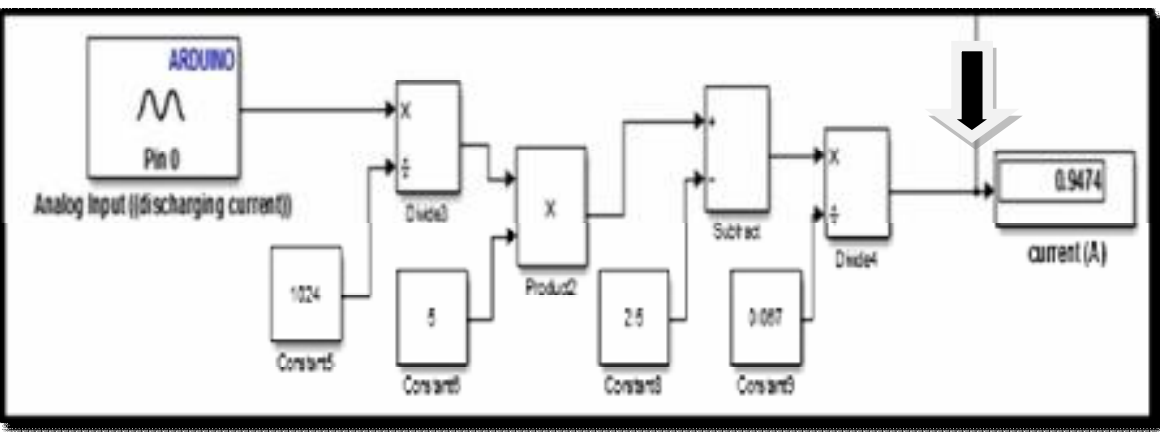

Fig.24: Connecting loads (Dc\Ac inverter and mobile charger)

Battery Volt as shown in the next figure is $(12.6 \mathrm{Vdc})$.

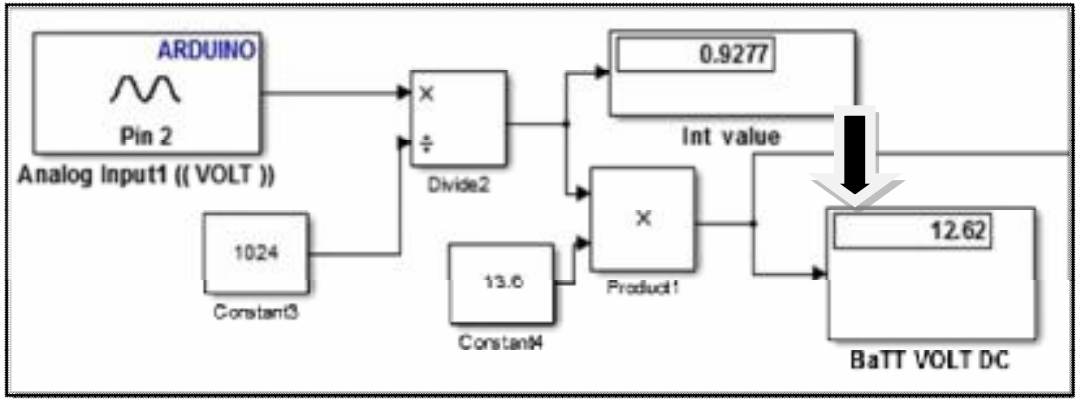

Fig.25: Battery Volt (Temperature effect).

Ambient temperature $45 \circ \mathrm{C}$.

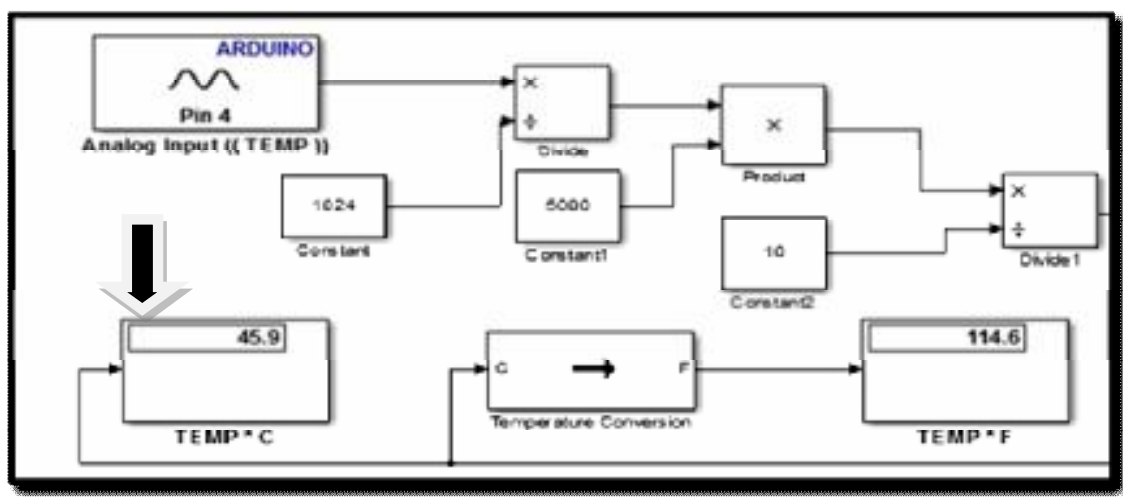

Fig.26: Ambient temperature of battery bank.

Because of the sudden increasing of the ambient temperature, the proposed charger controller optimized its output level. The optimization was done according to the range of temperature increasing and the FIS design as shown in Fig.27. 


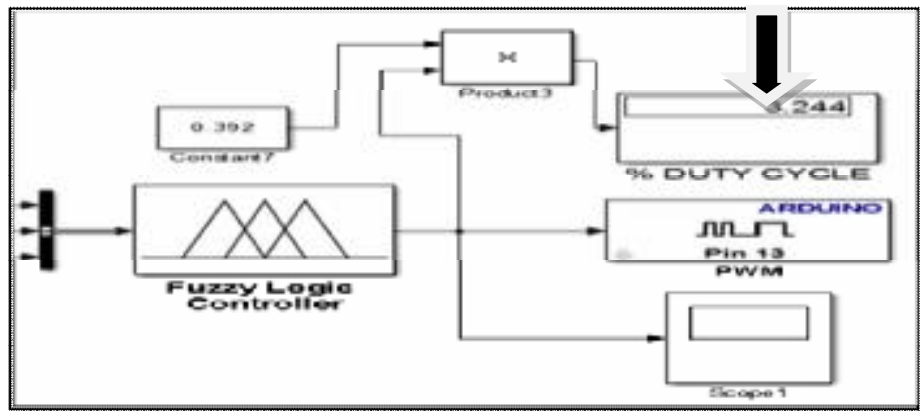

Fig.27: Output current with $3 \%$ duty cycle.

The three previous cases were gathered in the next table (the practical measurements and results of the proposed system response) and showed as bar chart inFig.28. The fast and smooth change in the duty cycle of the proposed system output was indicated. The proposed system was assembled and executed in its final hardware form as shown in Fig.29.

Table 2: collection of the practical results and measurements.

\begin{tabular}{|c|c|c|c|c|}
\hline Cases & Batt. $(\mathbf{V})$ & $\begin{array}{c}\text { Ambient } \\
\text { temp. } \circ \mathbf{C}\end{array}$ & $\begin{array}{c}\text { Current. } \\
(\mathbf{X} / \mathbf{1 0 0}) \mathbf{A}\end{array}$ & $\begin{array}{c}\text { PWM Level } \\
(\mathbf{0 - 2 5 5})\end{array}$ \\
\hline 1 & 12.14 & $21(\mathrm{Med})$. & $\mathbf{0}$ & 77 (Med.) \\
\hline 2 & 12.14 & $21($ Low $)$ & $\mathbf{8 7}$ & $190($ High) \\
\hline 3 & 12.6 & $45($ High) & $\mathbf{9 4}$ & 8 (Low) \\
\hline
\end{tabular}

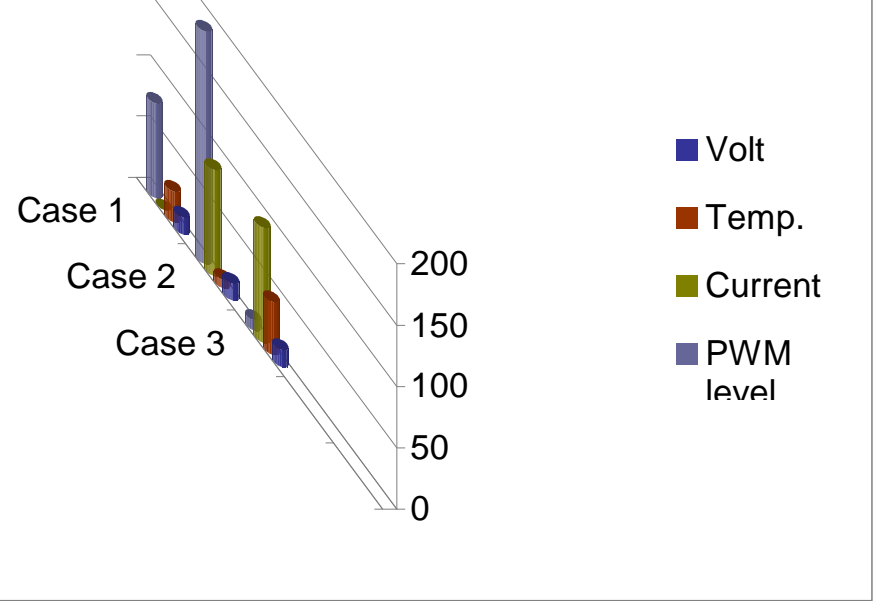

Fig.28: indication chart for the three cases of the practical results. 


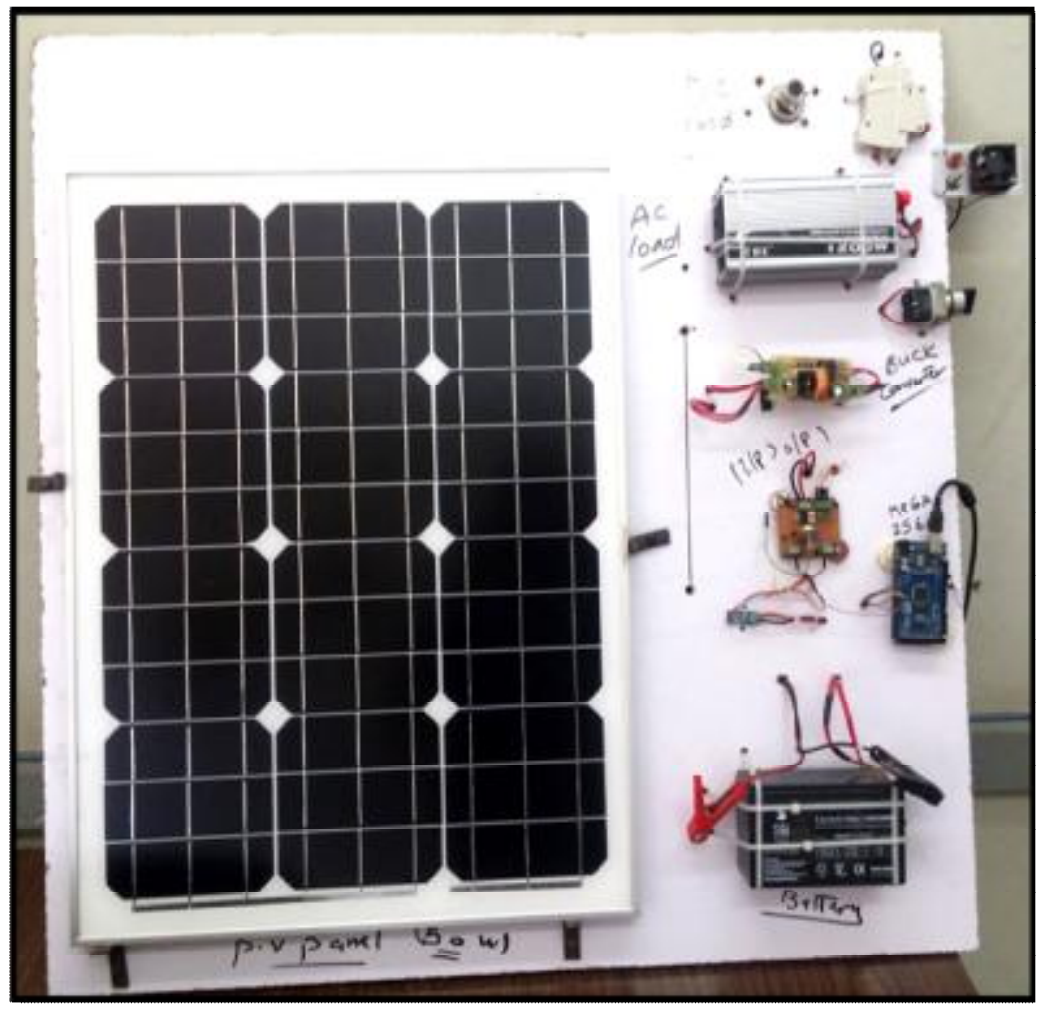

Fig 29: Hardware implementation photograph.

\section{CONCLUSIONS.}

The proposed system is supposed to be an improvement to the traditional PWM charger controller for Stand-Alone PV systems. It could achieve the following objectives:

1- Making the system smart by adding the measurement of the ambient temperature to the parameters of evaluating the battery bank conditions (not only the charging current and the battery volt). This was done without making the system complex.

2- By measuring and dividing the ambient temperature into three memberships function, the proposed system became able to control :

a- The battery discharging current as we could turn off any normal loads in the case of high temperature degrees. This could be done with the exception of any critical loads according to the application conditions.

b- The charging current coming from the PV panel to the battery to avoid the problems that occurs in working in high temperature degrees.

3- Without using sophisticated mathematical models and by the embedded FLC, the battery was fully charged by a stable and smooth output current. It has been done without permitting overcharge, sulfation, stratification and increasing the life time of the battery. 


\section{REFERENCES}

1. Tushar, K. Ghosh and Mark A. Prelas, "Energy Resources and Systems", Volume 2: Renewable Resources, Springer 2011.

2. Hisham, Mahmood, Dennis Michaelson, and Jin Jiang, "Control Strategy for a Standalone PV/Battery Hybrid System", Department of Electrical and Computer Engineering, University of Western Ontario, London, Ontario, Canada N6A 5B9, 978-1-4673-2421-2/12, 2012 IEEE.

3. James, P. Dunlop, "Batteries and Charge Control in Stand-Alone Photovoltaic Systems Fundamentals and Application", Florida Solar energy center \University of Central Florida, Jan 1997

4. David, Linden and Thomas B. Reddy, "Handbook of Batteries", Third Edition, McGraw-Hill, ISBN 0-07-135978-8.

5. John, Rushworth ,"Which solar charge controller: pwm or mppt", Visteon Energy,Available at https://www.victronenergy.com/blog/2014/07/21/which-solar-chargecontroller-pwm-or-mppt/, Accessed in 12-2017.

6. P.Dinesh, B.Kowshick, Pankaj Raghav.P, Ramesh.K.Govindarajan, G.Saravana Ilango, "Solar Power Based Intelligent Battery Charging System Compatible with Existing Home Inverters", National Institute of Technology, Tiruchirappalli, Tamilnadu, 978-0-7695-5146-3/13 , 2013 IEEE DOI 10.1109/TIIEC.2013.35.

7. Muhammad, Saad Rahman, "Buck Converter Design Issues", Master thesis in Electronic Devices At Linköping Institute of Technology, 2007, ISRN: LiTH-ISY-EX--06/3854--SE.

8. Patil, A. R., Atar K. D., Potdar A. A., Mudholkar R. R., "Embedded Fuzzy Module For Battery Charger Control", Dept. of Electronics, Shivaji University, Kolhapur, Maharashtra, India, Copyright to IJAREEIE, ISSN (Print) : 2320 - 3765, ISSN (Online): 2278 - 8875, Aug 2013.

9. "Design a Buck Converter with XMEGA", Atmel Corporation, Rev.: 42183A-AVR-09/2013, Available at http://www.microchip.com //wwwAppNotes/AppNotes.aspx?appnote=en592070, Accessed in 102016.

10. Muhammad, H. Rashid, Ph.D., "Power Electronics Handbook Devices, Circuits, and Applications", Third Edition, ELSEVIER, ISBN: 978-0-12382036-5.

11. Zainab, Almukhtar, "Fuzzy Logic Control for Stand-alone Photovoltaic Energy Conversion System, and Innovation in Renewable Energy", Saint Mary's University, Halifax, Nova Scotia in Partial Fulfillment of the Requirements for the Degree of Master of Technology Entrepreneurship and Innovation, June 29, 2016, Halifax, Nova Scotia.

12. Kevin, M. Passino and Stephen Yurkovich, "Fuzzy Control", Copyright 1998 Addison Wesley Longman, ISBN 0-201-18074-X 123456789 10-CRW-0100999897.

13. Samer, Said Ahmed Massoud,Mohieddine Benammar and Shehab Ahmed, "A Matlab/Simulink-Based Photovoltaic Array Model Employing SimPowerSystems Toolbox", Department of Electrical and Computer Engineering, Texas A\&M University at Qatar, Doha P.O. Box 23874, Journal of Energy and Power Engineering 6 (2012) 1965-1975. 


\section{Appendix 1 (DC - DC buck converter)}

Inductor Selection [7]:

$$
\begin{gathered}
L=D \times\left(V_{\text {in }}-V_{\text {out }}\right) /\left(I_{\text {ripple }} \times f_{\text {sw }}\right) \\
I_{\max }=I_{\text {load }}+\left(I_{\text {ripple }} / 2\right)
\end{gathered}
$$

Output Capacitor Selection [7]:

The ESR (Effective Series Resistance)

$$
\begin{gathered}
T_{o n}=D / f_{\text {sw }} \\
\Delta V=I_{\text {ripple }} \times E S R+\left(I_{\text {ripple }} \times \frac{T_{\text {on }}}{C_{\text {out }}}\right) \\
C_{\text {out }}=\left[\left(I_{\text {ripple }} \times \frac{D}{f_{\text {ow }}}\right) /\left(\Delta V-I_{\text {ripple }} \times \text { ESR }\right)\right.
\end{gathered}
$$

$C_{\text {out }}$ is the minimum output capacitor, $I_{\text {rippl }}$ is the estimated inductor ripple current, $\Delta V$ is the desired output voltage ripple, $D$ is Duty Cycle of the Buck converter, $f_{F w}$ is minimum switching frequency of the Buck converter, generated by drive circuit.

Freewheeling Diode Selection [7]:

$$
I_{D}=I_{\text {load }} \times(1-D)
$$

$I_{D}$ Is average forward current of the freewheeling diode, $D$ is Duty Cycle $I_{\text {lood }}$ is maximum output current ,

$$
P=I_{D} \times V_{f}
$$

Is forward voltage of the diode [9]. $V_{f}$

\section{Appendix 2 (PWM control using Arduino)}

$$
\begin{aligned}
& \text { Duty Cycle }=T_{\text {on }} \div\left(T_{\text {on }}+T_{\text {off }}\right) \\
& V_{\text {eff }}=V_{s} \times\left(T_{o}+T_{e}\right) \\
& 0 \leq \text { PWM output Level } \leq 255 \\
& \text { (11) } P W M_{\text {ostput }}=255 \times \frac{T o}{T o}=255 \times \frac{V \text { eff }}{V g}=255 \times \frac{V e f f}{\mathrm{~s}}
\end{aligned}
$$

